\title{
Short-term forecasts of French GDP: A dynamic factor model with targeted predictors
}

\author{
MARIe BesseC ${ }^{1}$
}

\begin{abstract}
In recent years, factor models have received increasing attention from both econometricians and practitioners in the forecasting of macroeconomic variables. In this context, Bai and $\mathrm{Ng}(2008)$ find an improvement in selecting indicators according to the forecast variable prior to factor estimation (targeted predictors). In particular, they propose using the LARS-EN algorithm to remove irrelevant predictors. In this paper, we adapt the Bai and Ng procedure to a setup in which data releases are delayed and staggered. In the pre-selection step, we replace actual data with estimates obtained on the basis of past information, where the structure of the available information replicates the one a forecaster would face in real time. We estimate on the reduced dataset the dynamic factor model of Giannone, Reichlin and Small (2008) and Doz, Giannone and Reichlin (2011), which is particularly suitable for the very short-term forecast of GDP. A pseudo real-time evaluation on French data shows the potential of our approach.
\end{abstract}

Keywords: GDP forecasting, factor models, large dataset, variable selection, targeted predictors. JEL classification: C22, E32, E37.

\footnotetext{
${ }^{1}$ Banque de France and LEDA-Université Paris Dauphine, marie.bessec@banque-france.fr I thank O. Bouabdallah, S. Dees, C. Doz, P. de Rougemont and an anonymous referee for their helpful comments and suggestions, as well as the participants to several seminars and conferences. This paper reflects the opinions of the author and does not necessarily express the views of the Banque de France.
} 


\section{Introduction}

Over the past decade, there has been growing interest in factor models in the forecasting of GDP and inflation rate. The change in the forecasting devices of Central Banks reflects the success of these models: In addition to the traditional bridge models or combination of bridge models, central banks are now using static or dynamic factor models to draw up their short-run scenarios. The trend was initiated by Stock and Watson $(1999,2002)$ and Giannone, Reichlin and Small (2008) at the US Federal Reserve and then includes the works by Angelini et al. (2011) at the European Central Bank, Altissimo et al. (2001, 2007 ) at the Banca d'Italia, Schumacher $(2007,2010)$ at the Bundesbank, D'Agostino et al. (2008) at the Central Bank of Ireland and Barhoumi, Darné and Ferrara (2010) at the Banque de France. A study of Rünstler et al. (2010) conducted within the Eurosystem also shows the usefulness of this approach in predicting short-term fluctuations of GDP in the euro area as well as ten individual countries including France.

Traditionally, factors are extracted from a large database which consists of hundreds of economic indicators giving more or less advanced information on the business cycle and are then used as explanatory variables in a regression model of the GDP growth rate. Since the theory is developed for a large number of variables $N$ and observations $T$, the natural tendency is to use as much data as are available for the estimation of factors. As indicated by Boivin and Ng (2006), this can pose several problems. First, factors are constructed regardless of the series to be forecast while some variables can be driven by factors less related to the targeted variable. Moreover, it might not be desirable to expand the dataset if the additional series contain little information on the factors prevailing in the database. If the idiosyncratic components are large or correlated with each other, additional variables may even impair the accuracy of the factor estimates and the forecast.

Based on this observation, Bai and Ng (2008) show empirically that there may be a gain in selecting indicators prior to factor estimation according to the forecast variable. Their Targeted Predictors method consists in removing from the database the variables which only contain noise or blocks of variables driven by a factor less correlated to the variable to be forecast. In their paper, a pre-selection method relying on the LARSEN algorithm (Zou and Hastie, 2005) gives the best results in forecasting inflation and real variables such as the industrial production index. Charpin (2009) and Schumacher (2010) implement this method to forecast French and German GDP growth. ${ }^{2}$ Schumacher

\footnotetext{
${ }^{2}$ The first paper focuses on the forecast of French GDP in the next, current and previous quarters. In the latter paper, Schumacher carries out simulations for German GDP at forecast horizons of up to four
} 
shows a gain compared to the traditional factor models and highlights the contribution of international variables for forecasting German GDP, which is not apparent without pre-selection. ${ }^{3}$

In this paper, we incorporate in the selection procedure a key issue that arises from the different timeliness of monthly indicators in the short run forecasting of GDP growth. Short-term indicators used as predictors of GDP have different publication lags. Soft indicators like survey data and financial variables are released during the reference month or a few days later, whereas hard data are published several weeks later (three weeks for the consumption of goods and six weeks for industrial production for instance). Without taking the publication lags into account, pre-selection would favor real indicators such as the industrial production index, which is highly correlated with GDP but published with a significant delay. This has a detrimental effect in earlier forecasting exercises.

This problem is even more severe when the forecast model is not horizon-specific. If a single equation of GDP is used with extrapolated predictors (the factors in our case), the targeted variable is the same regardless of the forecast horizon and the traditional preselection procedure would lead to the same specification in all cases. However, it seems more relevant to focus at longer horizons on leading indicators that convey the most advanced information on the cycle (in particular, financial or international variables, e.g. yield curve or stock price indices) and to use coincident indicators (e.g. GDP components such as IPI) for the last predictions.

In order to account for the increasing information flow up to the GDP release, we propose a simple adjustment of the Bai and Ng procedure. The LARS-EN algorithm is not applied to the full data (available in practice on the whole quarter only between two months and a few days before the release of quarterly accounts) but to the only information available at the time of the forecast of each quarter. To this end, the algorithm is applied to pseudo real-time data sets whose missing values at each horizon are forecast recursively on the basis of the past information and where the structure of the available information maps the one that a forecaster would face in real time.

The pre-screening of variables on the transformed data-sets makes it possible to take into account the availability of the monthly indicators at each forecast horizon. When the release date for the target variable is further in the future, this method penalizes indicators that are released with significant delay (hard data) in favor of variables with quarters.

${ }^{3}$ Caggiano, Kapetanios and Labhard (2011) also find an improvement when selecting a smaller subset of variables using the rules of Boivin and $\mathrm{Ng}$ (2006). They obtain more accurate estimates of GDP in the euro area and 7 European countries, including France, at a horizon of 1 to 12 quarters. 
short delays (soft data). When the release date for the target variable becomes closer (nowcast and backcast), estimated data are progressively replaced by actual numbers and the method favors variables more strongly correlated with GDP (hard data).

We then apply on the reduced dataset the dynamic factor model developed by Giannone, Reichlin and Small (2008) and estimated with the 2-step method of Doz, Giannone and Reichlin (2011). This representation provides a convenient framework for the shortrun GDP forecast by making it possible to update the GDP forecast with short-term indicators sampled at a higher frequency. It is possible to incorporate within quarter monthly information and produce macroeconomic forecasts several times during the quarter. Moreover, this approach is implementable when some observations are missing at the end of the sample due to publication lags through the application of the Kalman filter. ${ }^{4}$

This approach is implemented to forecast French GDP in the next, current and previous quarters with monthly updates. The factors are extracted from a database of monthly indicators, including survey balances, real indicators, financial variables and indicators on the international environment. The LARS-EN algorithm naturally favors survey and financial variables at the longest horizons and then gradually real variables, such as industrial production and external trade data, as the forecast horizon shortens. The contribution of financial variables at longer horizons is particularly large when the latest recession is taken into account in the evaluation period. A pseudo real-time evaluation over the last ten years shows an improvement on models estimated without pre-selection and with pre-selection neglecting the timeliness of the indicators and the forecast horizon.

The paper proceeds as follows. In the first part, we present the estimation and forecast framework proposed by Giannone et al. (2008) and Doz et al. (2011) and the new preselection approach. The dataset is described in the second section. The third part provides an assessment on the forecasting performance of factor models obtained with and without pre-selection. The last section concludes.

\section{The dynamic factor model with targeted predictors}

\subsection{The dynamic factor model}

The dynamic factor models allow a parsimonious description of the dynamics common to the observed variables (or co-movements of observed variables). These models generalize

\footnotetext{
${ }^{4}$ In this framework, Rünstler (2010) proposes an alternative adjustment of the Bai and Ng's method. He shows that the LARS method may not identify the appropriate predictors when ignoring the unbalanced data availability at the end of the sample. We find consistent results in this paper. He provides an alternative method for selecting an efficient set of predictors in a dynamic factor model with the forecast weights derived from the Kalman smoother.
} 
the static models. First, the common factors are autocorrelated (generally, their dynamics are modeled as a VAR or possibly as a VARMA). Second, the observed variables can be affected by the values of contemporary factors but also by their lagged values.

Consider a vector of $N$ stationary monthly series $X_{t}=\left(X_{1 t}, X_{2 t}, \ldots, X_{N t}\right)^{\prime}, t=$ $1, \ldots, T$ previously standardized to mean zero and variance one. We assume that the observed variables $X_{t}$ can be described as a function of a small number of unobservable latent variables, called factors, possibly their lags and an idiosyncratic component, specific to the series:

$$
X_{t}=\Lambda f_{t}+\varepsilon_{t} \quad t=1, \ldots, T
$$

where $f_{t}$ is a $r \times 1$ vector of latent factors, $\Lambda$ is a $N \times 1$ matrix of factor loadings and $\varepsilon_{t}$ is the idiosyncratic component at $t$.

Furthermore, factors are modeled as a VAR process of order $p$ :

$$
f_{t}=A_{1} f_{t-1}+\ldots+A_{p} f_{t-p}+B u_{t} \quad t=1, \ldots, T
$$

where $u_{t}$ i.i.d. $N(0,1)$ is a white noise of dimension $q$ (the dynamic shocks), $B$ is a $r \times q$ matrix and $A_{1}, \ldots, A_{p}$ are $r \times r$ matrices of parameters. It is useful to explicitly model the dynamics of the factors since equation (2) can be used to forecast the factors before the end of the quarter. The system of equations (1)-(2) can be cast in a state space representation. The measurement equation (1) describes the relationship between the observed variable $X_{t}$ and the unobserved state variable $f_{t}$. The state equation (2) describes how the hidden variables are generated from their lags and from innovations.

In this study, we use the two-step method proposed by Doz, Giannone and Reichlin (2011) to estimate the factors in the monthly frequency. Factors are first estimated by principal components on the balanced sub-sample, i.e. over the period when all the variables $X_{t}$ are known. The factors are then estimated over the entire range of observations including the period when some variables have missing observations. At this point, we apply the Kalman filter and smoother to the state space representation. To accommodate the missing observations at the end of the sample due to publication lags, the variance of the idiosyncratic noise related to the missing observations is set to infinity (this is equivalent to skipping these observations). The factors are then extended to the future with equation (2). The factors are finally averaged in order to obtain quarterly series and are incorporated into a linear regression model of the GDP growth rate:

$$
y_{t+h}=\mu+\delta f_{t+h}^{Q}+\eta_{t} \quad t=1, \ldots, T
$$


where $f_{t+h}^{Q}$ is the $r \times 1$ vector of quarterly factors. In this approach, we do not consider a horizon-specific model. A single equation is used with factors previously extrapolated from equation (2).

\subsection{The LARS-EN algorithm}

We still assume that a set of $N$ possible predictors $X_{t}$ observed for $t=1, \ldots, T$ is available for the estimation of the factors. The algorithm LARS-EN is a sequential backward selection procedure that selects among these $N$ variables the ones most correlated with the target variable while taking into account the information provided by the other predictors.

Let $S C R$ denote the residual sum of squares of the regression of the variable to be forecast $y_{t}$ on an intercept, possibly autoregressive terms $W_{t}$ and the predictors $X_{t}$ :

$$
y_{t}=\alpha^{\prime} W_{t}+\beta^{\prime} X_{t}+\varepsilon_{t} \quad t=1, \ldots, T
$$

where the predictors $X_{t}$ have been transformed in the same way as for the factor estimation (i.e. standardized to mean zero and variance one).

The EN criteria of Zou and Hastie (2005) can be written as follows:

$$
\min _{\beta} S C R+\lambda_{1} \sum_{i=1}^{N}\left|\beta_{i}\right|+\lambda_{2} \sum_{i=1}^{N} \beta_{i}^{2}
$$

where $\lambda_{1}$ and $\lambda_{2}$ penalize with the $L_{1}$ and $L_{2}$ norm of $\beta$. The EN penalty is a combination of the LASSO (least absolute shrinkage selection operator) and ridge penalties. The vector $\beta$ shrinks to the ridge estimate if $\lambda_{1}=0$ and to the LASSO estimate if $\lambda_{2}=0$. Zou and Hastie (2005) argue that it is more efficient to use a combination of these two rules for the following reason. The ridge estimate never sets the coefficients exactly to 0, i.e. never completely excludes the variables. On the other hand, the LASSO estimate is empirically dominated by the ridge estimate, when the predictors are highly correlated.

The LARS algorithm is an iterative process for finding the coefficient vector $\beta$ satisfying the criterion. At the first iteration, all the coefficients are set to 0 . In the following iterations, the variables are selected in order of importance taking into account the correlation with the regressors already included in set $A$ of selected predictors. We need to specify the parameters $\lambda_{1}$ and $\lambda_{2}$. We will assess later the sensitivity of the results to the choice of these two parameters. Instead of choosing a value for $\lambda_{1}$, it is possible to define the number of regressors $N_{A}$ to select among all the $N$ possible predictors. The algorithm LARS-EN retains the $N_{A}$ most important predictors and leaves out the $N-N_{A}$ remaining variables. ${ }^{5}$

\footnotetext{
${ }^{5}$ In this application of the LARS-EN algorithm, we are not interested in the estimated coefficient $\beta$
} 


\subsection{A real-time pre-selection of indicators}

The first official estimate of French quarterly GDP is published 45 days after the end of the quarter (e.g. in mid-May for the first quarter). The short-term forecaster usually delivers a first prediction of a given quarter seven months before the release date, at the beginning of the preceding quarter (e.g. in late October for the forecast of the first quarter). Then this forecast is updated every month to incorporate the new releases of monthly indicators related to activity. ${ }^{6}$ Overall, a sequence of eight forecasts is produced before the release of GDP. Figure 1 shows the timing of forecasts and the information available at the time of each forecast.

Figure 1. Monthly updating scheme of data releases

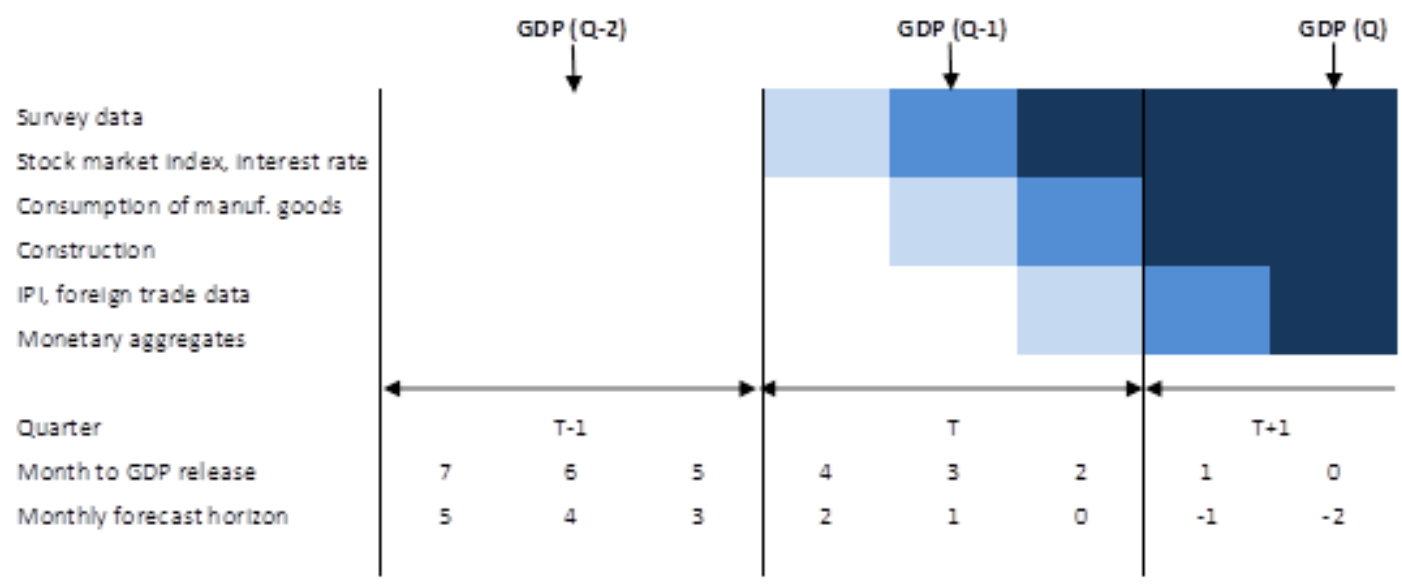

Indicotor ovoilobility
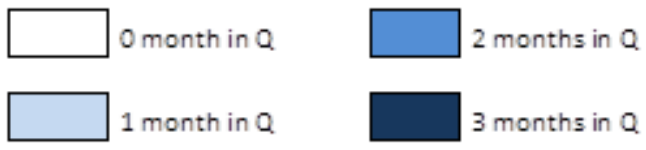

A few days before the release of GDP, the information set obviously incorporates a wider range of indicators on the reference quarter than at the very beginning of the exercise. Hence, the implementation of the LARS-EN algorithm must be adapted to account for the forecast horizon and the different publication lags. Since forecast equation (3) is the same regardless of the forecast horizon, the usual pre-selection procedure would lead to the same selection at every month. It would be more natural to favor indicators that convey the most advanced information on the cycle at the beginning of the exercise and coincident ones at the shortest horizons. Moreover, a pre-selection that ignores the

\footnotetext{
but only in the selection of variables.

${ }^{6}$ At the Banque de France, the forecasts are usually made at the end of the month after the publication of business surveys. This timing will be assumed in our forecast evaluation. At the ECB, an update also occurs in the middle of the month following the release of the bulk of hard data such as industrial production and external trade data.
} 
different timings of data releases would favor hard data, as discussed below. This is detrimental at the beginning of the forecasting exercise because real indicators are highly correlated with GDP but are obtained with a significant delay. ${ }^{7}$

To cope with these problems, we propose a simple adjustment of the Bai and $\mathrm{Ng}$ procedure. Instead of applying the LARS-EN algorithm to the series available today, we first reconstruct pseudo real-time data sets for each forecast horizon. Accordingly, we use the only available observations of monthly indicators at the time of the forecast while the missing observations are predicted. To this end, recursive forecasts are made with autoregressive processes. The order is chosen with the BIC criterion for each indicator. The range for $p$ is $\{1, \ldots, 12\}$ for monthly indicators and $\{1, \ldots, 4\}$ for quarterly ones. We extrapolate the monthly indicators from autoregressive models because the factors are also forecast on the basis of their past dynamics in the dynamic factor model (VAR), that is, on the past values of the indicators (factors are constructed as linear combinations of the variables belonging to the dataset). Finally, we convert these new series into quarterly data since the targeted variable (the GDP growth rate) is released on a quarterly basis.

Formally, each quarterly variable is constructed as follows:

$$
x_{t}^{Q}=\left(x_{t-2 \mid t-h-d}+x_{t-1 \mid t-h-d}+x_{t \mid t-h-d}\right) \quad t=\max (h+d, 0)+1, \ldots,\lfloor T / 3\rfloor
$$

where $x_{t}$ is the monthly indicator, $x_{t}^{Q}$ is the monthly series containing the quarterly value in the third month of the quarter and unobserved otherwise, $d$ is the publication lag of $x_{t}$ (between 0 and 2 months in this application) and $h$ is the monthly forecast horizon from 5 (forecast at the beginning of the previous quarter) to -2 (forecast in the subsequent quarter) as shown in Figure 1. If $t-i>t-h-d, i=0,1,2, x_{t-i \mid t-h-d}=E\left(x_{t-i} \mid I_{t-h-d}\right)$ and $x_{t-i \mid t-h-d}=x_{t-i}$ otherwise with $I_{t}=\left(x_{t}, x_{t-1}, \ldots\right)$ the present and past information on $x$ at time $t$.

For example, in the second month of the quarter to be forecast, the quarterly series derived from a monthly indicator released with a lag of one month (e.g., the consumption of goods) will be constructed as follows:

$$
x_{t}^{Q}=\left(x_{t-2}+x_{t-1 \mid t-2}+x_{t \mid t-2}\right) \quad t=3, \ldots,\lfloor T / 3\rfloor
$$

We use this method for each forecast horizon $h=-2, \ldots, 5$. Then we apply the LARS-EN algorithm to each of the eight resulting datasets. Finally, we estimate the factor model in the usual way from the selected variables.

\footnotetext{
${ }^{7}$ For example, the three months of the industrial production index on the reference quarter are available only 40 days after the end of the reference quarter, i.e. only a few days before the GDP release. By contrast, the three months of the survey variables are published at the end of the quarter (see Figure 1).
} 


\section{The data}

The database consists of French GDP growth and 96 predictors (120 if the transformations of the variables are counted). ${ }^{8}$ Four groups of variables are considered:

- Survey variables in manufacturing, services, retail trade, construction as well as the consumer surveys in France.

- Indicators of real activity: GDP components or indicators of these components such as household consumption of goods, registrations of new vehicles, exports of goods on the demand side and the main components of industrial production on the supply side.

- Nominal variables - monetary and financial: Several stock price indices, monetary aggregates, interest rates, interest rate spreads, market volatility and price indices.

- International variables: Nominal bilateral and effective euro exchange rates, key macro-economic indicators for Germany and the United States.

The survey variables and most nominal indicators are released during the month to which they refer, while real variables have a publication lag of one or two months. International indicators consisting of survey, nominal and real variables are released with varying delays.

In short-run forecasting, considerable attention is devoted to the first two groups of variables and these variables are usually incorporated into bridge models of GDP. For example, the Banque de France regularly uses the macro-sector model OPTIM to forecast French GDP growth in the current and next quarters. This model involves survey data and real indicators. The only nominal and international variables are the consumption price index and the euro dollar exchange rate. ${ }^{9}$ However, financial and international variables can play a significant role in bridge equations, either as direct predictors of GDP or in auxiliary models used to fill the missing values of the predictors. Among forecasters using this approach, we can refer to Diron (2008), Andersson and D'Agostino (2008) at the European Central Bank for the euro area, Heyer et al. (2008) at OFCE for France, and Bulligan, Marcellino and Venditti (2012) at the Banca d'Italia for forecasting the Italian GDP and its components. The euro growth indicator published by the Euroframe network also relies on a bridge model with regressors chosen among international/financial variables in addition to survey variables. We will see in the following that financial and international variables are selected by the algorithm for the longest horizons.

The sample period is 1990Q1-2010Q4. Our dataset was downloaded on 29 July 2011. We do not use a real-time dataset, which is not available for such a broad set of indicators. Most variables are monthly and they are seasonally adjusted. Several survey variables

\footnotetext{
${ }^{8}$ The variables are listed in Appendix 1, together with their publication lag and their transformation. ${ }^{9}$ See Irac and Sedillot (2002) and Barhoumi et al. (2011) for a presentation of the model.
} 
are published on a quarterly basis. The missing observations of the quarterly survey variables for the estimation of the factors are filled with the Kalman filter (applying the same treatment as the one for the missing observations at the end of the sample). Some financial variables sampled at a higher frequency are converted into monthly data by averaging the observations over the month. A study of the stationarity of the data was performed. Survey variables are found to be stationary, real and financial variables integrated of order one with the exception of the yield curve, the financial stress index and the volatility index VIX. The $I(1)$ variables are transformed as a 3-month growth rate or difference (see Appendix 1). Moreover, survey variables are considered in level and in 3-month difference at the previous month. All series are standardized to mean zero and variance one.

\section{Empirical results}

\subsection{Empirical design}

We assess the quality of the forecasts made 7 months ahead to a few days before the GDP release.

The evaluation is conducted in real conditions, i.e., out of the estimation period. The models are estimated from the observations available from 1990 and the forecasting performance is assessed over the last observations of our sample, from 2000Q1 to 2010Q4 and for each forecast horizon. The parameters of the models are estimated recursively using the only information available at the time of the forecast. At this level, we replicate the pattern of missing values at the end of the sample to take into account the time of publication of the variables, as shown in Figure 1. Moreover, the selection of variables ${ }^{10}$ is performed in real-time: The reconstruction of the pseudo-datasets is conducted at every recursion as described previously. The order of the AR process is chosen according to the $\mathrm{BIC}$ criterion for each indicator and at each time of the out-of-sample period. The LARSEN algorithm is then applied to the only available observations of the target variable at each recursion. Nevertheless, as mentioned above, we use data published in July 2011 and hence ignore the revisions to earlier data release.

More precisely, the approach is as follows. The first quarter of 2000 is forecast conditional on the information available in October 1999, November 1999, and so on up to May 2000. To this aim, we first select the variables with the LARS-EN algorithm applied to the reconstructed data over different samples given the time release of GDP: 1990Q1-

\footnotetext{
${ }^{10}$ We have used the Matlab code of the LARS-EN algorithm provided by Karl Skoglund.
} 
1999Q2 for the forecast made in October 1999, 1990Q1-1999Q3 for the forecasts made from November 1999 to January 2000, and 1990Q1-1999Q4 from February 2000 to May 2000. The factor model is then estimated on the reduced data-set following Doz et al. (2011) and used for prediction. In June, we make no forecast for the first quarter of 2000 because the growth rate of GDP in the first quarter is released in mid-May. Similarly, we produce eight forecasts of the GDP growth rate in the second quarter of 2000 from the available data in January 2000 to August 2000. These calculations are replicated up to the last quarter of the out-of-sample period.

We finally get eight sets of forecasts for the quarters 2000Q1 to 2010Q4 conditional on the information available from 7 months to a few days before the release of GDP (in the following, M-7, M-6,..,M-0 refer to the forecasts made 7 months, 6 months,... and a few days before the GDP release). The forecast accuracy is measured with the root mean squared forecast error (RMSFE), the mean absolute forecast error (MAFE) and the Pesaran-Timmerman test. This test assesses the directional accuracy of a forecast, i.e. in our application the ability of the model to predict acceleration or deceleration of activity.

Using these criteria, the factor model with our pre-selection procedure is compared to four benchmark models. First, we consider an autoregressive process with a constant and a random walk with a drift. In the case of the AR process, the lag length is selected at each recursion of the out-of-sample exercise with the BIC criterion and we use a one-periodahead model iterated forward for the desired number of periods. The forecast derived from the random walk is obtained as the average of the past GDP growth rate. To assess the gain due to the pre-selection, we also compare the RMSFE to those of traditional factor models without pre-selection. Finally, we examine how the factor model performs if the pre-selection is made on the complete data set, i.e. without predicting the missing values of the indicators at the time of the forecast before pre-selection. This last benchmark is useful as it highlights the importance of considering the evolution of information in the pre-selection.

There are a number of parameters to be specified related to the factor model and the LARS-EN algorithm. In the factor models, we determine the number of factors with the criteria of Bai and $\mathrm{Ng}(2002,2007)$ : The number of static factors $r$ is determined by minimizing the information criterion IC2 in Bai and Ng (2002). The number of dynamic factors $q$ is chosen according to the information criterion given by Bai and $\mathrm{Ng}$ (2007) with $m=1$. The maximum number of static factor is set to 8 and the number of shocks $q$ is chosen in the range $[1, \min (5, r)]$. The order $p$ of the VAR on the factors is chosen with the usual BIC criterion in the range $\{1,2,3\}$. This is also done at each recursion 
in the out-of-sample exercise. Following Bai and $\mathrm{Ng}$ (2008), we also use different sets of parameters for the implementation of the LARS-EN algorithm ${ }^{11}: N_{A}=\{20,30, \ldots, 80\}$ and $\lambda_{2}=\{0.1,0.25,0.5,0.75,1\}$. We will compare the forecast performance of the factor models for all pairs of $N_{A}$ and $\lambda_{2}$.

\subsection{Selection of explanatory variables}

Figure 2 presents the selections of variables by the LARS-EN algorithm in the recursive exercise at each forecast horizon. For the sake of parsimony, we focus on the results obtained for $\lambda_{2}=0.25$ and a number of variables $N_{A}=30^{12}$. The list of the first selected variables on the entire sample (i.e. at the last recursion) is given in Appendix 2.

A first glance at Figures (2a) and (2b) reveals that the composition of the selection according to the delay of publication or the type of variable is relatively stable over the out-of-sample period. Yet, the share of international and financial variables increases over the last decade, especially when the great recession in 2008-09 is included in the selection. For the forecast of the next quarter (from 7 to 5 months before the GDP release), the proportion of the financial and international variables in the selection for 2010 is $32 \%$ and $21 \%$ respectively, as opposed to $18 \%$ and $11 \%$ in 2000 . For the forecast of the current quarter (from 4 to 2 months before the GDP release), the weight of these two groups also increases, from $13 \%$ and $3 \%$ in 2000 to $18 \%$ and $15 \%$ in 2010 . When backcasting GDP, $20 \%$ of the selected variables belong to the international group in 2010 against $7 \%$ in 2000 but the share of nominal variables is quite stable.

By contrast, the selection procedure leads to very different datasets according to the forecast horizon (in the traditional approach, we would only use the selection derived from the full dataset which is described in the last graph in Figures 2a and 2b). As expected, variables with short publication lags play a prominent role at longer horizons when the availability of hard data for the reference quarter is scarce. Real indicators are highly correlated with activity but released with a significant delay, which explains why they are discarded at the beginning of the forecasting exercise. Variables with short publication lags are gradually replaced by indicators released later as the forecast horizon gets shorter. In line with this finding, the selection consists mostly of survey variables and financial indicators for the longest horizons. By contrast, real indicators are discarded at

\footnotetext{
${ }^{11}$ Bai and $\mathrm{Ng}(2008)$ consider $\lambda_{2}=\{0.25,0.5,1.5\}$ and $N_{A}=30$ in their application to US inflation with $N=132$ potential predictors. Schumacher (2010) considers $\lambda_{2}=\{0.1,0.25,0.5,1.5\}$ and $N_{A}=$ $\{30,60,90,120,180,240,300\}$ in an application to the German GDP with alternatively $N=123$ and $N=531$ variables.

${ }^{12}$ For this pair of parameters, the factor models with pre-selection perform well at all forecast horizons, as shown later.
} 
the beginning of the forecast but their weight increases gradually as the forecast horizon diminishes. ${ }^{13}$

As seen in Appendix 2, the first selected variables for the forecast of the next quarter (the first three forecasts) consist of survey variables (forward-looking survey balances of the household survey and production expectations in industry), financial series (the yield spread in France and in the US, interest rates, stock indices, a stress index) and IFO and ZEW business expectations as international indicators. Some of them are the components of popular leading indices for France such as the Conference Board's leading economic index ${ }^{14}$ or the OECD's Composite Leading Indicator ${ }^{15}$. Within the quarter to predict, business and consumers survey data, international variables such as the American IPI (released one month earlier than its French counterpart) and IFO and ZEW survey balances are the first variables selected by the algorithm. The components of GDP (industrial production, consumption of goods and external trade series) are predominant in the selection used in the last two forecasts. This finding is consistent with the practice of forecasters: IPI and foreign trade data are usually taken into account in the models when they are at least available on the first two months of the quarter.

\subsection{Out-of-sample results}

We now turn to the forecast evaluation of the models. Table 1 (left panel) reports the RMSFE, MAFE criteria and the Pesaran-Timmermann statistics for the factor models with pre-selection following the approach proposed in this paper. Only the results for $\lambda_{2}=0.25$ are presented in the interests of simplicity (but the full results are provided in Appendix 3). However, we examine further the impact of the number of pre-selected variables on the results.

The quality of prediction is relatively poor for the longest horizons. The average

\footnotetext{
${ }^{13}$ These findings are consistent with the conclusions in Bańbura and Rünstler (2011). They derive forecast weights for assessing the role of individual series in the dynamic factor model and show that real activity data become much less relevant once their publication lag is taken into account, while business surveys and financial variables play a more important role.

${ }^{14}$ This indicator calculated by the Conference Board is a leading indicator intended to forecast economic activity. The components of the LEI for France are the yield spread, 10-year minus Day-Day loans, the stock Price SBF 250 index, building permits issued, new unemployment claims, new industrial orders, production expectations, and the ratio deflator of manufacturing value added to unit labor cost.

${ }^{15}$ The OECD composite leading indicator is designed to provide early signals of turning points between expansions and slowdowns of economic activity. Country CLIs are compiled by averaging the following series (de-trended and normalized): Consumer confidence, expected production in industry, prospects for industrial sector, opinion about the level of finished goods stocks in industry, the SBF 250 share price index, the Eonia interest rate, interest rate spread, new passenger car registrations, terms of trade and new job vacancies.
} 
absolute error reaches up to 0.37 point $^{16}$ over the last decade and the proportion of correct directions is very low. Moreover, the factor models generally fail to beat significantly the AR benchmark as shown by the modified Diebold and Mariano test of Harvey et al. (1997) in Appendix 3. However, the results improve gradually with the increase in monthly information: The average absolute error reaches 0.22 point at the end of the current quarter and nearly 0.15 point a few days before the publication of GDP. At this point, the proportion of correct senses of variation ranges from $63 \%$ to $77 \%$. This improvement is also clear in Figure 3. In the left-hand graph, the forecast is quite inaccurate seven months before the release of GDP. By contrast, in the right-hand graph, the forecast made a few days before the GDP release tracks GDP very accurately. ${ }^{17}$

Figure 3. Out-of-sample forecasts of the French GDP growth rate Forecast of the French GDP growth in M-7

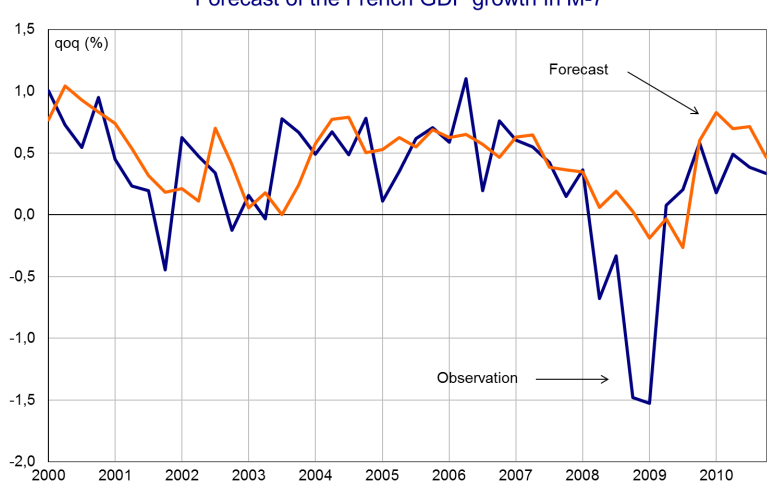
Forecast of the French GDP growth in M-0

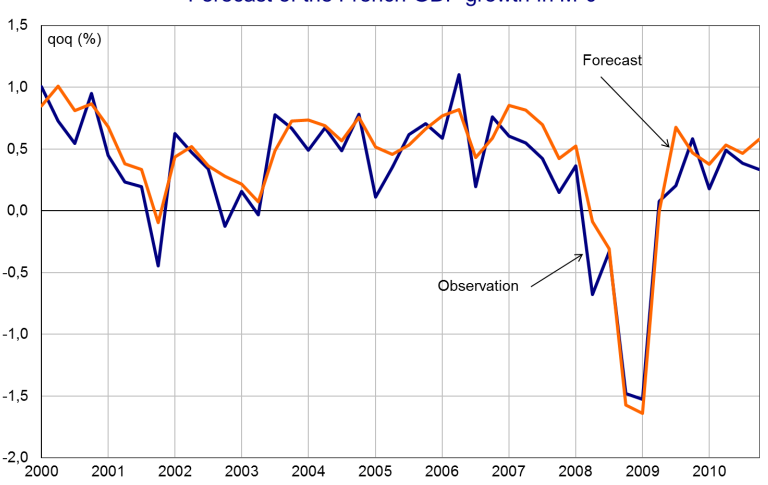

The ratios of the RMSFE of our factor models against the four benchmark models are reported in Table 1 (right panel). A ratio below one indicates a gain relative to the reference model. There is an improvement upon the usual reference processes and the gain increases as the GDP release gets closer. Compared to the autoregressive process (column AR in Table 1), the RMSE is about 20\% lower for the next-quarter forecasts and improves by more than $40 \%$ for the last two forecasts over the whole period. Like Bai and Ng (2008) and Schumacher (2010), we also find a gain in pre-selecting variables (column WS), even if it is found decreasing as the forecast horizon is shorter. The gain reaches $24 \%$ when forecasting the next quarter. The best results are generally obtained with few variables $\left(N_{A}=30,40\right.$ or 50$)$. Moreover, the RMSFE ratios are found to be lower than one in $74 \%$ of the 280 cases examined (i.e. the 35 possible pairs $\left\{N_{A}, \lambda_{2}\right\}$ and the 8 forecast horizons).

Moreover, the results in Table 1 highlight the importance of accounting for the timeliness of the indicators and the forecast horizon in the pre-selection step (column SFI). For

\footnotetext{
${ }^{16}$ This average error is large compared with the average qoq growth rate of French GDP of $0.5 \%$.

${ }^{17}$ The results for the eight forecast horizons and all the specifications are provided in Appendix 4.
} 
the current and next quarter forecasts, our selection approach nearly always outperforms a pre-selection on the complete data set. The gain stands at $22 \%$ for the next and current quarter forecast over 2000-2010. This may explain the low performance of the LARS selection in Rünstler (2010) when the publication lag of the series is neglected. The gain over a pre-selection on the complete dataset decreases as the horizon shortens. In the last but one forecast, the new pre-selection approach slightly outperforms the usual one only for $N_{A}=30$. This finding is not surprising since the dataset used in our pre-selection procedure gets closer to the complete dataset for short horizons. The results are naturally identical for the last forecast since the pre-selection is made on the complete data set in both cases. Overall, the ratio of RMSFE is below one in $79 \%$ of the 245 cases $^{18}$ over the whole decade.

Figure 4. Distributions of RMSFE
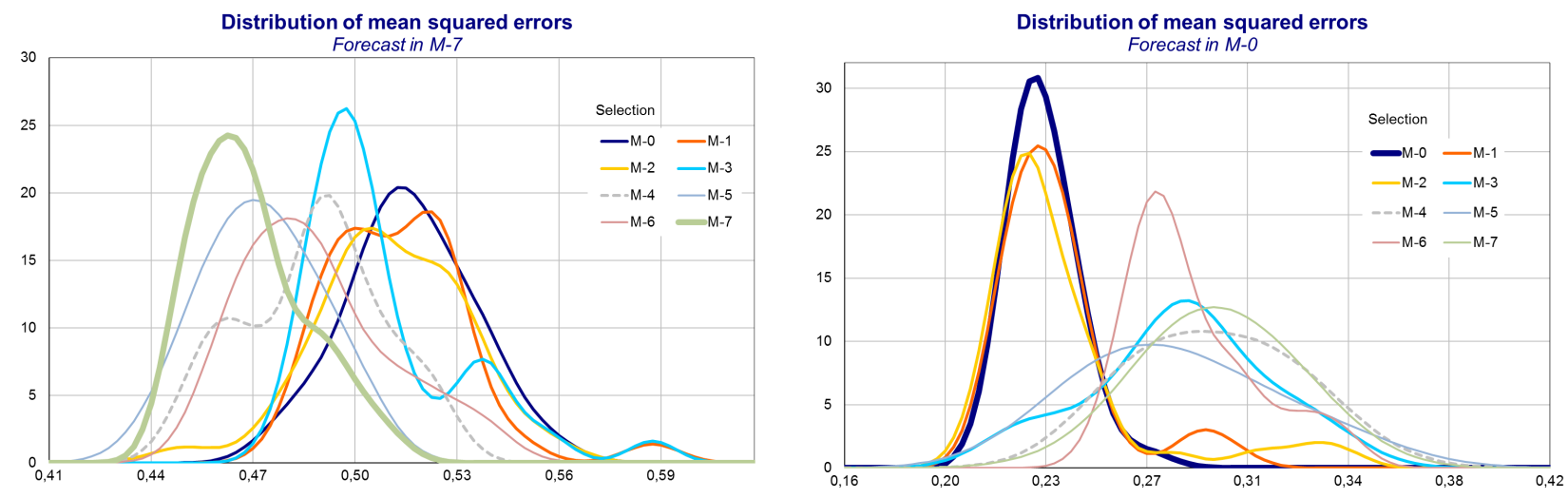

The gain of the new pre-selection approach is also evident from Figure 4. We plot the distributions of the mean squared errors for predictions made seven months before the release of GDP (left graph) and a few days before (right graph). These distributions are constructed from the RMSFEs obtained for the different values of $N_{A}$ and $\lambda_{2}$. The different curves depict the results with a pre-selection made conditional on the information available at the different monthly horizons. At the beginning of the forecasting exercise, the left-most distribution corresponds to a pre-selection conducted with data in M-7. The distributions shift towards the right as information is integrated into the selection, indicating that the forecast accuracy deteriorates. The less favorable distribution corresponds to a pre-selection carried out with complete information (i.e. without extrapolating the monthly indicators to fill the missing observations 7 months before the GDP release). By contrast, shortly before the publication of GDP, the pre-selection conducted with full information leads to better results. Distributions now shift to the right when the pre-selection is performed with less information.

\footnotetext{
${ }^{18}$ We exclude the case $h=0$ since the results are identical by construction at this horizon.
} 


\section{Concluding remarks}

Bai and Ng (2008) suggest that pre-selecting indicators prior to factor estimation can improve the forecast accuracy of factor models. In this paper, we apply this technique to the short-run forecast of GDP growth.

In order to account for the timeliness of the indicators and the forecast horizon, we apply the selection procedure to pseudo real-time data sets at each forecast horizon. We implement this method to nowcast the French GDP growth rate. Financial variables and survey variables are predominant at longer horizons, while the weight of real indicators increases at shorter ones. A pseudo real-time evaluation over the last decade shows a gain relative to factor models without pre-selection or with pre-selection made on the full dataset at least for large horizons.

An obvious limitation of this analysis is that it is not performed on real-time data. To remove a possible impact of revisions of the data on our results, we could replicate this exercise on predictors less subject to revisions such as survey data. Moreover, it could be interesting to compare our approach with the selection procedure proposed by Rünstler (2010). This is left for future research. 


\section{References}

Angelini E., Camba-Méndez G., Giannone D., Rünstler G., Reichlin L. (2011). Shortterm forecasts of Euro Area GDP growth, the Econometrics Journal, 14(1), C25-C44.

Altissimo F., Bassanetti A., Cristadoro R., Forni M., Hallin M., Lippi M., Reichlin L., Veronese G. (2001). A real time coincident indicator for the euro area business cycle, CEPR Discussion Paper Series No. 3108.

Altissimo F., Cristadoro R., Forni M., Lippi M., Veronese G. (2007). New Eurocoin: Tracking economic growth in real time, Banca d'Italia No. 631.

Andersson M., D'Agostino A. (2008). Are sectoral stock prices useful for predicting Euro Area GDP?, ECB working paper No. 876 .

Bai J., Ng S. (2008). Forecasting economic time series using targeted predictors, Journal of Econometrics, 146, 304-317.

Bańbura M., Rünstler G. (2011). A look into the factor model black box: Publication lags and the role of hard and soft data in forecasting GDP ", International Journal of Forecasting, 27(2), 333-346.

Barhoumi K., Darné O., Ferrara L. (2010). Are disaggregate data useful for factor analysis in forecasting French GDP?, Journal of Forecasting, 29(1-2), 132-144.

Barhoumi K., Darné O., Ferrara L., Pluyaud B. (2011). Monthly forecasting of French GDP: A revised version of the OPTIM model, forthcoming in Bulletin of Economic Research.

Bai J., Ng S. (2002). Determining the number of factors in approximate factor models, Econometrica, 70, 191-221.

Bai J., Ng S. (2007). Determining the number of primitive shocks in factor models, Journal on Business and Economic Statistics, 25, 52-60.

Boivin J., Ng S. (2006). Are more data always better for factor analysis, Journal of Econometrics, 132, 169-194.

Bulligan G., Marcellino M., Venditti F. (2012). Forecasting economic activity with higher frequency targeted predictors, working paper no.847, Banca d'Italia.

Caggiano G., Kapetanios G., Labhard V. (2011). Are more data always better for factor analysis? Results for the Euro Area, the six largest euro area countries and the UK, Journal of Forecasting, 30(8), 736-752.

Charpin F. (2009). Estimation précoce de la croissance. De la régression LARS au modèle à facteurs, Revue de l'OFCE, 108, 31-48.

D'Agostino A., McQuinn K., O'Brien D. (2008). Nowcasting Irish GDP, Research Technical Paper 9/RT/08, Central Bank of Ireland. 
Diron M. (2008). Short-term forecasts of euro area real GDP growth: an assessment of real-time performance based on vintage data, Journal of Forecasting, 27(5), 371-390.

Doz C., Giannone D., Reichlin L. (2011). A two-step estimator for large approximate dynamic factor models based on Kalman filtering, Journal of Econometrics, 164, 188-205.

Efron B., Hastie I., Johnstone R., Tibshirani R. (2004). Least Angle Regression, Annals of Statistics, 32, 407-499.

Giannone D., Reichlin L., Small D. (2008). Nowcasting GDP and inflation: The real-time informational content of macroeconomic data releases, Journal of Monetary Economics, 55(4), 665-676.

Harvey D., Leybourne S., Newbold P. (1997). Testing the equality of prediction mean squared errors, International Journal of Forecasting, 13, 281-291.

Heyer E., Blot C., Cochard M., Péléraux H., Plane M. (2008). France : Entrée dans le tunnel ? Scénarios 2008-09 pour l'économie française", Revue de l'OFCE, 107, 175-248.

Irac D., Sédillot F. (2002). Short run assessment of French economic activity using OPTIM, Note d'Etudes et de Recherche de la Banque de France, No.088.

Pesaran M.H., Timmermann A. (1992). A simple nonparametric test of predictive performance, Journal of Business and Economic Statistics, 10, 461-465.

Rünstler G., Barhoumi K., Cristadoro R, Reijer A. D., Jakaitiene A., Jelonek P., Rua A., Ruth K., Benk S., Nieuwenhuyze C. V. (2009). Short-term forecasting of GDP using large monthly data sets: a pseudo real-time forecast evaluation exercise, Journal of forecasting, 28(7), 595-611.

Rünstler G. (2010). On the design of data sets for forecasting with dynamic factor models, WIFO working paper 376.

Schumacher C. (2007). Forecasting German GDP using alternative factor models based on large datasets, Journal of Forecasting, 26, 271-302.

Schumacher C. (2010). Factor forecasting using international targeted predictors: The case of German GDP, Economic Letters, 107, 95-98.

Stock J., Watson M. (1999). Forecasting inflation, Journal of Monetary Economics, 44, 293-335.

Stock J., Watson M. (2002). Macroeconomic Forecasting using diffusion indexes, Journal of Business and Economic Statistics, 20, 147-162.

Zou H., Hastie T. (2005). Regularization and variable selection via the elastic net, Journal of the Royal Society, 67, 301-320. 

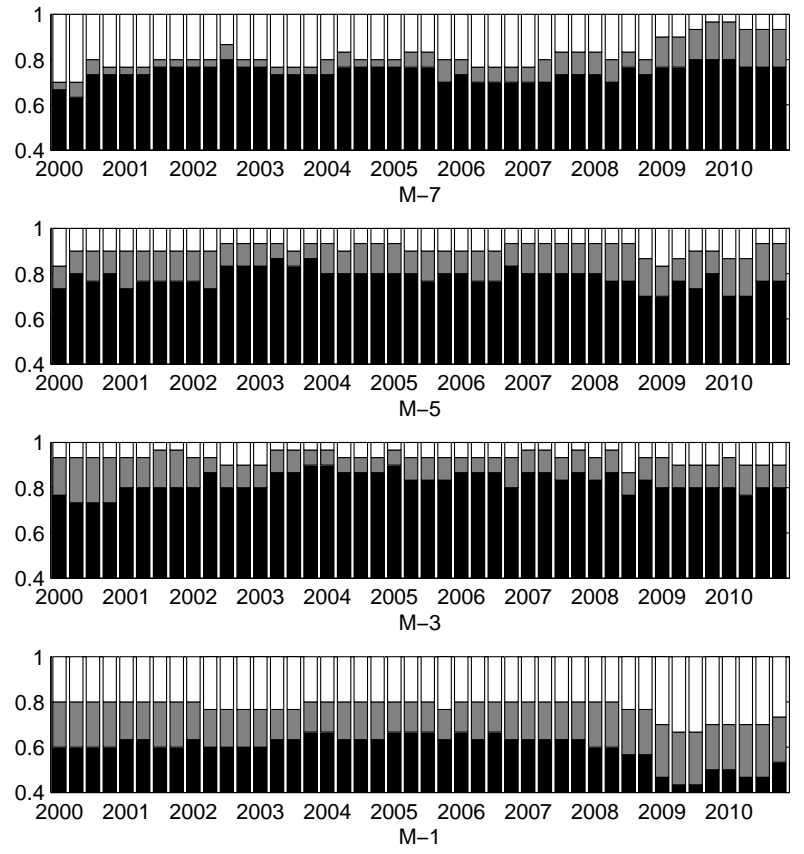

delay $=0$ month
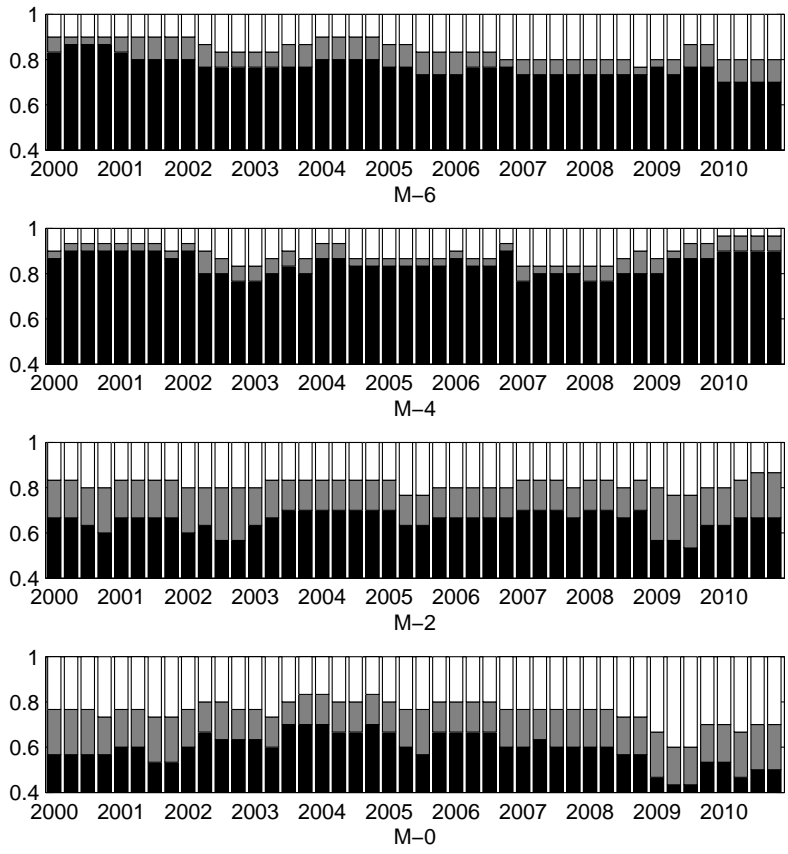
delay=2 months

Figure 2a. Delays of publication
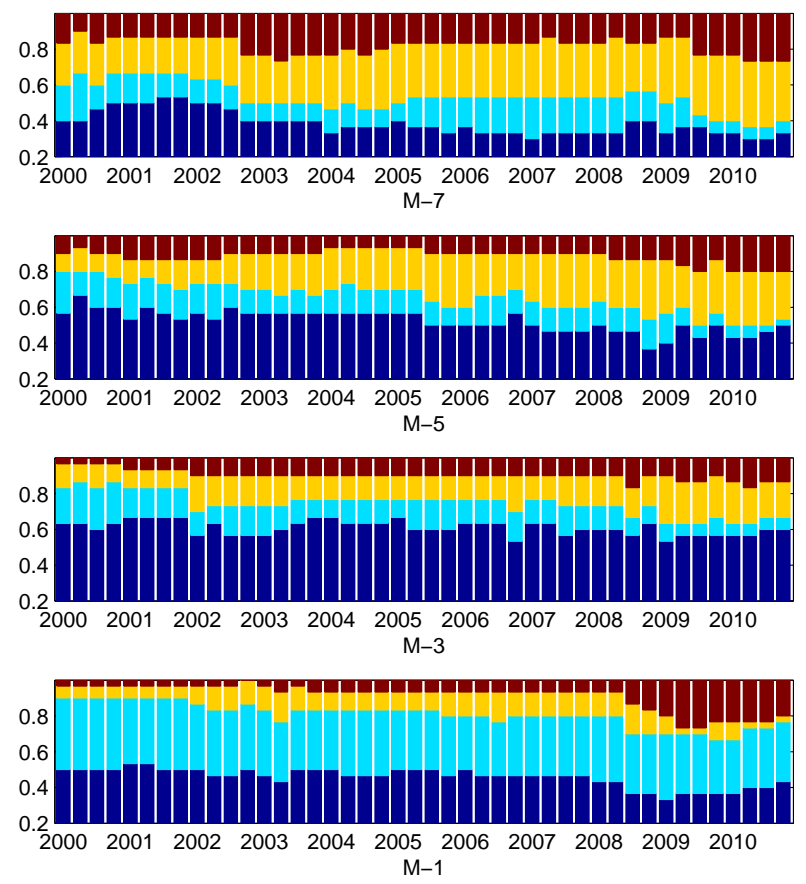
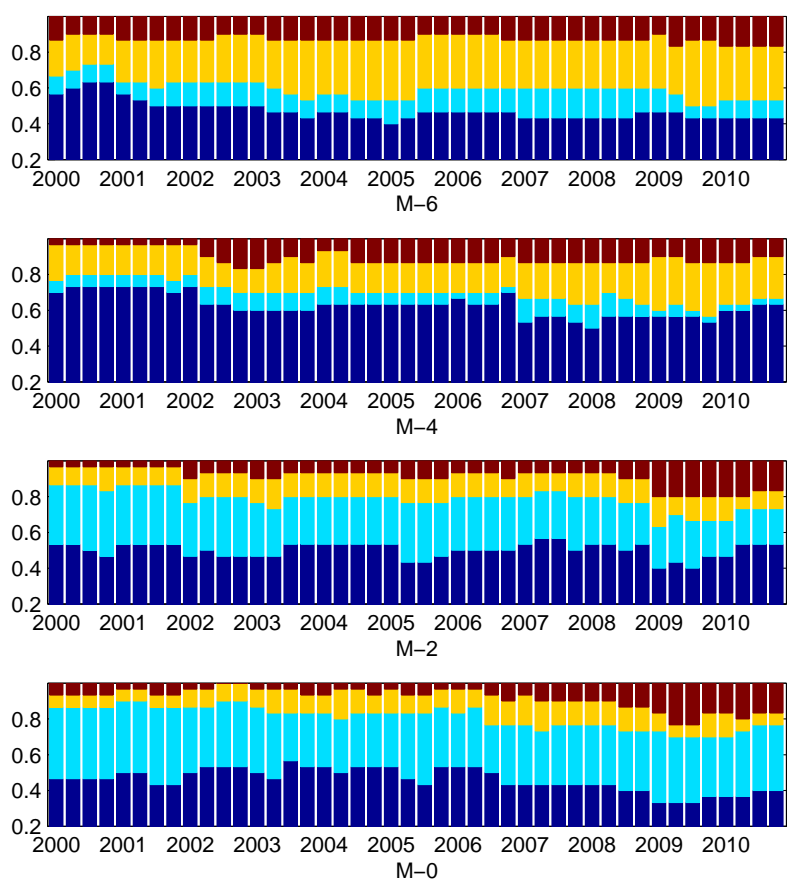
$\mathrm{M}-0$

international

Figure 2b. Types of variables 
Table 1. Out-of-sample evaluation of forecasts with variable pre-selection

\begin{tabular}{|c|c|c|c|c|c|c|c|c|}
\hline & \multicolumn{3}{|c|}{ Criteria (\%) } & \multicolumn{4}{|c|}{ Relative RMSFE } \\
\hline $\mathrm{M}$ & $N_{A}$ & RMSFE & MAFE & SIGN & SFI & WS & $\mathrm{AR}$ & RW \\
\hline \multirow{7}{*}{-7} & 80 & 0.46 & 0.35 & $0.56(0.22)$ & 0.92 & 0.88 & 0.82 & 0.86 \\
\hline & 70 & 0.47 & 0.34 & $0.53(0.32)$ & 0.90 & 0.91 & 0.85 & 0.89 \\
\hline & 60 & 0.47 & 0.34 & $0.58(0.14)$ & 0.91 & 0.90 & 0.84 & 0.87 \\
\hline & 50 & 0.47 & 0.35 & $0.49(0.56)$ & 0.98 & 0.90 & 0.84 & 0.87 \\
\hline & 40 & 0.45 & 0.34 & $0.63(0.04)$ & 0.86 & 0.87 & 0.81 & 0.85 \\
\hline & 30 & 0.45 & 0.33 & $0.53(0.32)$ & 0.87 & 0.87 & 0.82 & 0.85 \\
\hline & 20 & 0.49 & 0.37 & $0.51(0.44)$ & 0.92 & 0.95 & 0.89 & 0.93 \\
\hline \multirow{7}{*}{-6} & 80 & 0.45 & 0.33 & $0.53(0.32)$ & 0.91 & 0.87 & 0.90 & 0.85 \\
\hline & 70 & 0.42 & 0.31 & $0.58(0.14)$ & 0.85 & 0.81 & 0.84 & 0.79 \\
\hline & 60 & 0.39 & 0.30 & $0.60(0.08)$ & 0.78 & 0.76 & 0.79 & 0.74 \\
\hline & 50 & 0.42 & 0.32 & $0.58(0.14)$ & 0.88 & 0.81 & 0.85 & 0.79 \\
\hline & 40 & 0.44 & 0.32 & $0.58(0.14)$ & 0.94 & 0.84 & 0.88 & 0.82 \\
\hline & 30 & 0.43 & 0.31 & $0.60(0.08)$ & 0.85 & 0.83 & 0.87 & 0.81 \\
\hline & 20 & 0.51 & 0.36 & $0.51(0.44)$ & 0.96 & 0.98 & 1.02 & 0.95 \\
\hline \multirow{7}{*}{-5} & 80 & 0.43 & 0.31 & $0.53(0.32)$ & 0.92 & 0.95 & 0.87 & 0.81 \\
\hline & 70 & 0.43 & 0.31 & $0.49(0.56)$ & 0.90 & 0.95 & 0.87 & 0.81 \\
\hline & 60 & 0.43 & 0.32 & $0.47(0.68)$ & 0.90 & 0.95 & 0.86 & 0.81 \\
\hline & 50 & 0.42 & 0.31 & $0.51(0.44)$ & 0.89 & 0.91 & 0.84 & 0.78 \\
\hline & 40 & 0.39 & 0.29 & $0.65(0.02)$ & 0.86 & 0.85 & 0.78 & 0.73 \\
\hline & 30 & 0.39 & 0.28 & $0.58(0.14)$ & 0.82 & 0.87 & 0.79 & 0.74 \\
\hline & 20 & 0.42 & 0.31 & $0.56(0.22)$ & 0.83 & 0.92 & 0.84 & 0.79 \\
\hline \multirow{7}{*}{-4} & 80 & 0.37 & 0.28 & $0.56(0.22)$ & 1.01 & 1.00 & 0.75 & 0.70 \\
\hline & 70 & 0.33 & 0.25 & $0.56(0.22)$ & 0.79 & 0.89 & 0.67 & 0.62 \\
\hline & 60 & 0.34 & 0.25 & $0.60(0.08)$ & 0.88 & 0.91 & 0.68 & 0.64 \\
\hline & 50 & 0.37 & 0.27 & $0.60(0.08)$ & 0.93 & 0.98 & 0.73 & 0.69 \\
\hline & 40 & 0.37 & 0.28 & $0.60(0.08)$ & 0.94 & 1.00 & 0.74 & 0.70 \\
\hline & 30 & 0.34 & 0.26 & $0.58(0.14)$ & 0.78 & 0.91 & 0.68 & 0.63 \\
\hline & 20 & 0.39 & 0.29 & $0.65(0.02)$ & 0.86 & 1.04 & 0.78 & 0.72 \\
\hline \multirow{7}{*}{-3} & 80 & 0.36 & 0.26 & $0.60(0.08)$ & 0.95 & 1.02 & 0.87 & 0.67 \\
\hline & 70 & 0.32 & 0.24 & $0.70(0.00)$ & 0.90 & 0.91 & 0.78 & 0.60 \\
\hline & 60 & 0.38 & 0.28 & $0.56(0.22)$ & 1.01 & 1.10 & 0.94 & 0.72 \\
\hline & 50 & 0.36 & 0.28 & $0.51(0.44)$ & 1.09 & 1.04 & 0.88 & 0.68 \\
\hline & 40 & 0.37 & 0.28 & $0.60(0.08)$ & 1.02 & 1.06 & 0.91 & 0.70 \\
\hline & 30 & 0.33 & 0.25 & $0.56(0.22)$ & 0.84 & 0.94 & 0.80 & 0.62 \\
\hline & 20 & 0.36 & 0.28 & $0.53(0.32)$ & 0.97 & 1.04 & 0.88 & 0.68 \\
\hline \multirow{7}{*}{-2} & 80 & 0.33 & 0.26 & $0.67(0.01)$ & 0.99 & 1.03 & 0.80 & 0.62 \\
\hline & 70 & 0.32 & 0.24 & $0.60(0.08)$ & 0.98 & 0.99 & 0.77 & 0.59 \\
\hline & 60 & 0.29 & 0.22 & $0.70(0.00)$ & 0.85 & 0.90 & 0.70 & 0.54 \\
\hline & 50 & 0.30 & 0.23 & $0.65(0.02)$ & 0.92 & 0.95 & 0.74 & 0.57 \\
\hline & 40 & 0.32 & 0.24 & $0.65(0.02)$ & 0.94 & 1.00 & 0.78 & 0.60 \\
\hline & 30 & 0.32 & 0.24 & $0.63(0.04)$ & 0.90 & 1.00 & 0.78 & 0.60 \\
\hline & 20 & 0.33 & 0.24 & $0.65(0.02)$ & 1.03 & 1.02 & 0.80 & 0.61 \\
\hline \multirow{7}{*}{-1} & 80 & 0.25 & 0.19 & $0.65(0.02)$ & 1.05 & 0.96 & 0.61 & 0.47 \\
\hline & 70 & 0.27 & 0.21 & $0.60(0.08)$ & 1.15 & 1.04 & 0.66 & 0.51 \\
\hline & 60 & 0.24 & 0.19 & $0.65(0.02)$ & 1.02 & 0.93 & 0.59 & 0.45 \\
\hline & 50 & 0.25 & 0.19 & $0.74(0.00)$ & 1.01 & 0.95 & 0.60 & 0.46 \\
\hline & 40 & 0.26 & 0.19 & $0.70(0.00)$ & 1.00 & 1.01 & 0.63 & 0.49 \\
\hline & 30 & 0.27 & 0.21 & $0.72(0.00)$ & 0.98 & 1.04 & 0.65 & 0.50 \\
\hline & 20 & 0.27 & 0.22 & $0.67(0.01)$ & 1.00 & 1.06 & 0.67 & 0.51 \\
\hline \multirow{7}{*}{0} & 80 & 0.22 & 0.17 & $0.72(0.00)$ & 1.00 & 0.94 & 0.54 & 0.42 \\
\hline & 70 & 0.22 & 0.18 & $0.72(0.00)$ & 1.00 & 0.94 & 0.54 & 0.42 \\
\hline & 60 & 0.23 & 0.18 & $0.63(0.04)$ & 1.00 & 0.97 & 0.56 & 0.43 \\
\hline & 50 & 0.23 & 0.17 & $0.77(0.00)$ & 1.00 & 0.96 & 0.55 & 0.43 \\
\hline & 40 & 0.23 & 0.18 & $0.72(0.00)$ & 1.00 & 0.99 & 0.57 & 0.44 \\
\hline & 30 & 0.24 & 0.20 & $0.72(0.00)$ & 1.00 & 1.02 & 0.59 & 0.45 \\
\hline & 20 & 0.23 & 0.19 & $0.72(0.00)$ & 1.00 & 0.99 & 0.57 & 0.44 \\
\hline
\end{tabular}

Note: The left panel of the table provides the evaluation criteria for the forecasts of the model with an horizon-specific pre-selection. The RMSFE and MAFE criteria measure the dispersion and average amplitude of the forecast errors. The directional accuracy test of Pesaran and Timmermann (1992) in the column SIGN assesses the models' capacity to predict the sign of variation of the series (for GDP growth, the ability to predict the acceleration or deceleration of activity). The right panel presents the ratios of the RMSFEs obtained in the factor model with real-time pre-selection to the RMSFE of the factor model with pre-selection on the full dataset (column SFI), to the RMSFE of the factor model without pre-selection (WS), to the RMSFE of an autoregressive process (AR) and to the RMSFE of a random walk (RW). 
Appendix 1. Data sources and descriptions

\begin{tabular}{|c|c|}
\hline No. & Type \\
\hline 1 & 1 \\
\hline 2 & 1 \\
\hline 3 & 1 \\
\hline 4 & 1 \\
\hline 5 & 1 \\
\hline 6 & 1 \\
\hline 7 & 1 \\
\hline 8 & 1 \\
\hline 9 & 1 \\
\hline 10 & 1 \\
\hline 11 & 1 \\
\hline 13 & 1 \\
\hline 14 & 1 \\
\hline 15 & 1 \\
\hline 16 & 1 \\
\hline 17 & 1 \\
\hline 18 & 1 \\
\hline 19 & 1 \\
\hline 20 & 1 \\
\hline 21 & 1 \\
\hline 22 & 1 \\
\hline 23 & 1 \\
\hline 26 & 1 \\
\hline 27 & 1 \\
\hline 28 & 1 \\
\hline 29 & 2 \\
\hline 30 & 2 \\
\hline 31 & 2 \\
\hline 32 & 2 \\
\hline 33 & 2 \\
\hline 34 & 2 \\
\hline 35 & 2 \\
\hline 36 & 2 \\
\hline 37 & 2 \\
\hline 38 & 2 \\
\hline 39 & 2 \\
\hline 40 & 2 \\
\hline 41 & 2 \\
\hline 42 & 2 \\
\hline 43 & 2 \\
\hline 44 & 2 \\
\hline 45 & 2 \\
\hline 46 & 2 \\
\hline 47 & 2 \\
\hline 51 & 3 \\
\hline 52 & 3 \\
\hline 53 & 3 \\
\hline 54 & 3 \\
\hline 55 & 3 \\
\hline 56 & 3 \\
\hline 57 & 3 \\
\hline 58 & 3 \\
\hline 59 & 3 \\
\hline 60 & 3 \\
\hline 61 & 3 \\
\hline 62 & 3 \\
\hline 63 & 3 \\
\hline 64 & 3 \\
\hline 65 & 3 \\
\hline 66 & 3 \\
\hline 67 & 3 \\
\hline 68 & 3 \\
\hline 69 & 3 \\
\hline 70 & 3 \\
\hline 71 & 3 \\
\hline 72 & 3 \\
\hline 73 & 3 \\
\hline 74 & 3 \\
\hline & 4 \\
\hline 76 & 4 \\
\hline 77 & 4 \\
\hline 78 & 4 \\
\hline 79 & 4 \\
\hline 80 & 4 \\
\hline 81 & 4 \\
\hline & 4 \\
\hline 83 & 4 \\
\hline 84 & 4 \\
\hline 85 & 4 \\
\hline 86 & 4 \\
\hline 87 & 4 \\
\hline 88 & 4 \\
\hline 89 & 4 \\
\hline 90 & 4 \\
\hline 91 & 4 \\
\hline 92 & 4 \\
\hline & 4 \\
\hline 94 & 4 \\
\hline 95 & 4 \\
\hline
\end{tabular}

Note: In the column type, the code 1 refers to survey data, 2 to real variables, 3 to nominal variables and 4 to international indicators. 


\begin{tabular}{|c|c|c|c|}
\hline M-7 & M-6 & M-5 & M-4 \\
\hline Business expectation (ZEW) & Gal prod exp - Industry & Business expectations (IFO) & Gal prod exp - Industry \\
\hline Gal prod exp - Industry & Business expectations (IFO) & Gal prod exp - Industry & Business exp (IFO) \\
\hline Business expectations (IFO) & Business expectations (ZEW) & Business expectations (ZEW) & Expected demand - Industry \\
\hline Exp financial sit - Households & Stress index & Order - Industry $(\Delta)$ & Business expectations (ZEW) \\
\hline DAX & Major purchases - Households & Major purchases - Households & IP manufacturing US \\
\hline Major purchases - Households & Price Earning Ratio (US) & Exp financial sit - Households & Exp activity Services $(\Delta)$ \\
\hline SBF 250 & Past financial sit - Households & Past financial sit - Households & Past prod - Building $(\Delta)$ \\
\hline Employment US & Past employment Building $(\Delta)$ & Retail sales US & Order - Industry $(\Delta)$ \\
\hline IP manufacturing US & Order - Industry $(\Delta)$ & Stress index & Order - Building $(\Delta)$ \\
\hline Yield curve in US & DAX & Exp prod - Industry $(\Delta)$ & Stress index \\
\hline Dow Jones & Yield curve in US & Order - Building $(\Delta)$ & Expected activity Services \\
\hline Current outlook (IFO) & Order - Building $(\Delta)$ & Past employment Building $(\Delta)$ & Major purchases - Households \\
\hline Gal prod exp Industry $(\Delta)$ & Loans & euro/uk & Exp financial sit - Households \\
\hline CUR - Building & Real estate interest rate & Past prod Building $(\Delta)$ & Dow Jones \\
\hline Consumption textile & IP - car & Topix & Exp gal eco sit - Households \\
\hline Order - Retail $(\Delta)$ & SBF250 & DAX & Gal prod exp - Retail \\
\hline eurostoxx 50 & Exp activity Services $(\Delta)$ & Exp gal eco sit - Households & Expected prod - Industry \\
\hline Real estate interest rate & Expected demand - Services & Past gal eco sit - Households & Order - Retail $(\Delta)$ \\
\hline PMI manufacturing US & M3 & Yield curve in FR & Exp prod - Industry $(\Delta)$ \\
\hline Past sales - Retail & PMI manuf US & Employment US & Topix \\
\hline Yield curve in FR & Yield curve in FR & Oil & $10 \mathrm{Y}$ interest rate \\
\hline Business outlook (ZEW) & IP - construction & Yield curve in US & Past employment Building $(\Delta)$ \\
\hline M2 - US & IP - total industry & SBF 250 & Yield curve in US \\
\hline $10 \mathrm{Y}$ interest rate & Expected activity - Services & Unemployment US & euro/uk \\
\hline FTSE & euro/uk & Foreign order Industry $(\Delta)$ & IP - coke and refined petroleum \\
\hline Unemployment - under 25 & CUR - Building & Gal prod exp Industry $(\Delta)$ & Past financial sit - Households \\
\hline Expected activity Services $(\Delta)$ & Gal prod exp Industry $(\Delta)$ & Exp employment Retail $(\Delta)$ & Past operating balance results - \\
\hline Consump other manuf goods & Exp financial sit - Households & M2 & Brent crude - 1 month fwd \\
\hline Expected activity - Services & Exp fin sit - Households $(\Delta)$ & Expected prod Building $(\Delta)$ & Past prod Industry $(\Delta)$ \\
\hline M3 & Expected demand Services $(\Delta)$ & CUR - Building & Exp employment Retail $(\Delta)$ \\
\hline
\end{tabular}

\begin{tabular}{|c|c|c|c|}
\hline M-3 & M-2 & M-1 & M-0 \\
\hline Gal prod exp - Industry & Business expectations (IFO) & IP - manufacturing & IP - manufacturing \\
\hline Business expectations (IFO) & Gal prod exp - Industry & IP - total industry & IP - total industry \\
\hline Expected production - Industry & Expected production - Industry & IP - other manufacturing & IP - other manufacturing \\
\hline IP manufacturing US & IP - manufacturing & Gal prod exp - Industry & Gal prod exp - Industry \\
\hline Business expectations (ZEW) & IP - other manufacturing & Expected production - Industry & Expected production - Industry \\
\hline Order - Industry $(\Delta)$ & IP manufacturing US & Business expectations (IFO) & Exports of goods \\
\hline Expected demand - Services & Business expectations (ZEW) & Exports of goods & Expected demand - Services \\
\hline Past production - Building $(\Delta)$ & Expected demand - Services & Business expectations (ZEW) & Business expectations (ZEW) \\
\hline Exp activity - Services $(\Delta)$ & Order - Industry $(\Delta)$ & Expected demand - Services & Consumption manuf goods \\
\hline Order - Building $(\Delta)$ & Order - Building $(\Delta)$ & Order - Building $(\Delta)$ & Order - Building $(\Delta)$ \\
\hline Past employm - Building $(\Delta)$ & Unemployment US & Consumption manuf goods & Unemployment US \\
\hline Expected demand - Industry & Exp gal eco sit - Households & Unemployment US & IP - equipment \\
\hline Exp gal eco sit - Households & Past production - Building $(\Delta)$ & Past production - Building $(\Delta)$ & Exp gal eco sit - Households \\
\hline Stress index & Consumption manuf goods & Exp gal eco sit - Households & Expected activity - Services \\
\hline Major purchases - Households & Exp activity - Services $(\Delta)$ & Exp financial sit - Households & Major purchases - Households \\
\hline Exp production - Industry $(\Delta)$ & Major purchases - Households & Employment US & Employment US \\
\hline Exp financial sit - Households & Exp financial sit - Households & Major purchases - Households & Exp financial sit - Households \\
\hline Car registrations & Job vacancies & Job vacancies & Consumption of goods \\
\hline Dow Jones & Car registrations & Expected activity - Services & Past production - Building $(\Delta)$ \\
\hline Order - Retail trade $(\Delta)$ & Employment US & Consumption house durables & Job vacancies \\
\hline Exp employment - Retail $(\Delta)$ & Exp production - Industry $(\Delta)$ & Consumption of goods & Consumption house durables \\
\hline Gal prod exp - Retail & Past employm - Building $(\Delta)$ & IP - car & Gal prod exp - Retail \\
\hline Topix & IP - car & Gal prod exp - Retail & Housing Prices US \\
\hline eurostoxx 50 & Gal prod exp - Retail & Exp production - Industry $(\Delta)$ & IP - car \\
\hline Job vacancies & Order - Retail trade $(\Delta)$ & Housing Prices US & Expected demand - Industry \\
\hline DAX & Expected employm - Retail $(\Delta)$ & Exp activity - Services $(\Delta)$ & M1 \\
\hline Expected activity - Services & Brent crude $-1 \mathrm{M}$ fwd & Exp production - Building $(\Delta)$ & Import DE \\
\hline Past production - Industry & Dow Jones & IP - manufacturing DE & Retail sales \\
\hline M1 & Expected activity - Services & Car registrations & $1 \mathrm{Y}$ interest rate \\
\hline Housing Prices US & Expected demand - Industry & $10 \mathrm{Y}$ interest rate & Foreign order - Industry \\
\hline
\end{tabular}

Note: This table reports the first 30 selected variables over 1990Q1-2010Q4. 
Appendix 3. Out-of-sample evaluation over 2000Q1 - 2010Q4

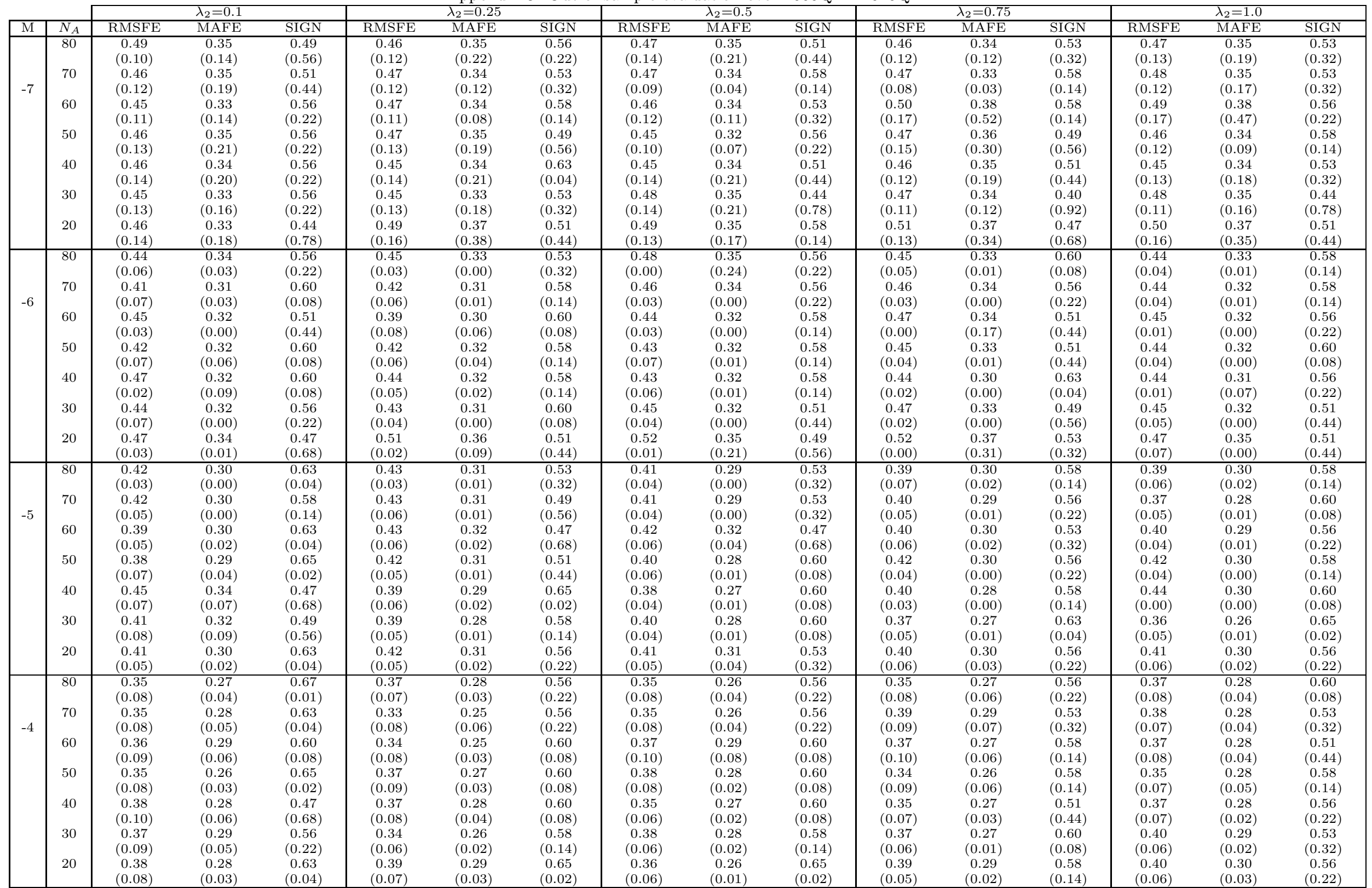

Note: This table reports the RMSFE and MAFE criteria and in brackets the associated p-value of the Diebold Mariano test with the small sample correction of Harvey et al. (1997) to assess whether the forecast is significantly better than in the benchmark AR model. The Pesaran-Timmermann statistics and its p-value are also given (column SIGN). 
Appendix 3 (continued). Out-of-sample evaluation over 2000Q1 - 2010Q4

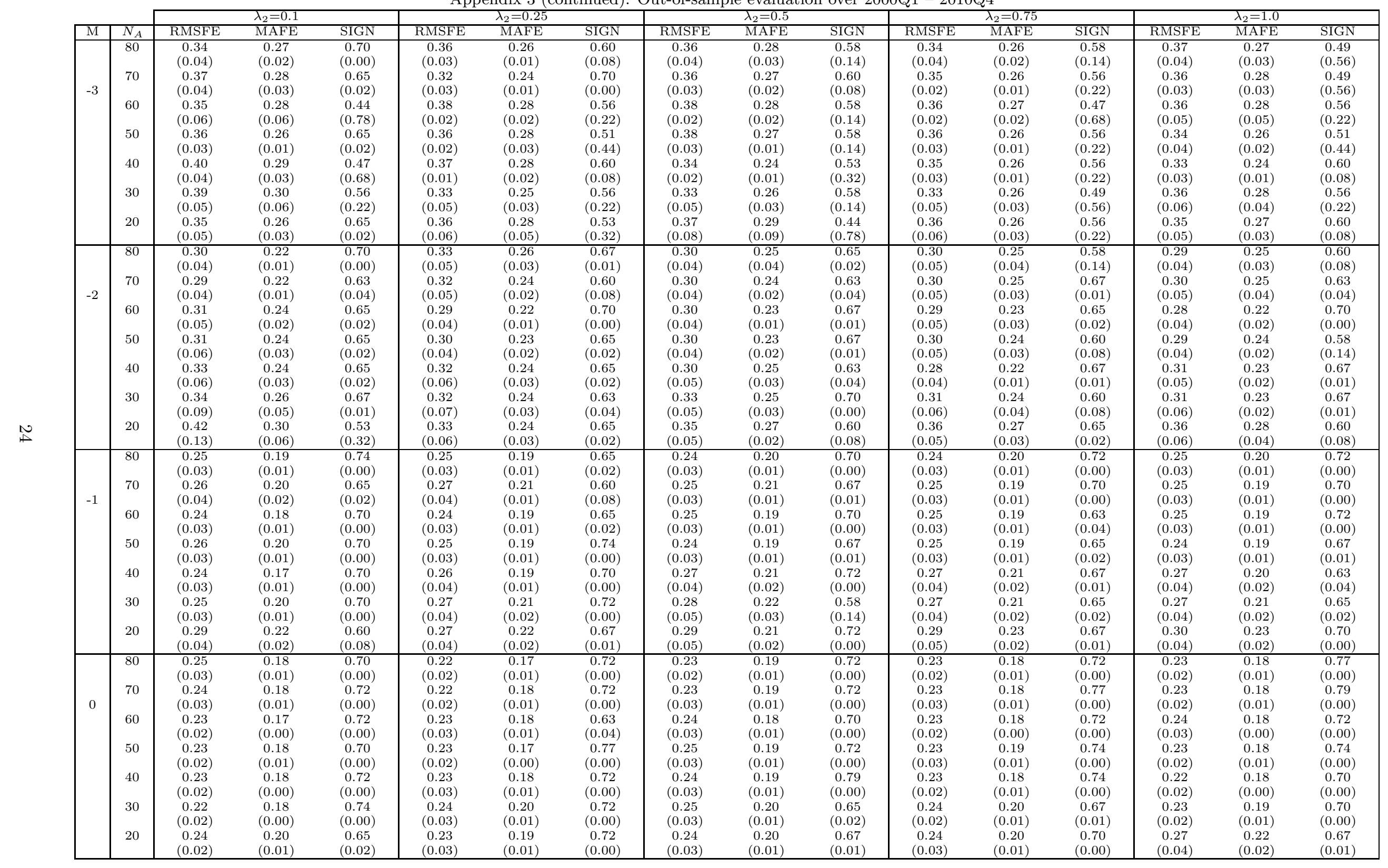

Note: This table reports the RMSFE and MAFE criteria and in brackets the associated p-value of the Diebold Mariano test with the small sample correction of Harvey et al. (1997) to assess whether the forecast is significantly better than in the benchmark AR model. The Pesaran-Timmermann statistics and its p-value are also given (column SIGN). 
Appendix 4. Out-of-sample forecasts of French GDP growth

Forecast of the French GDP growth in M-7

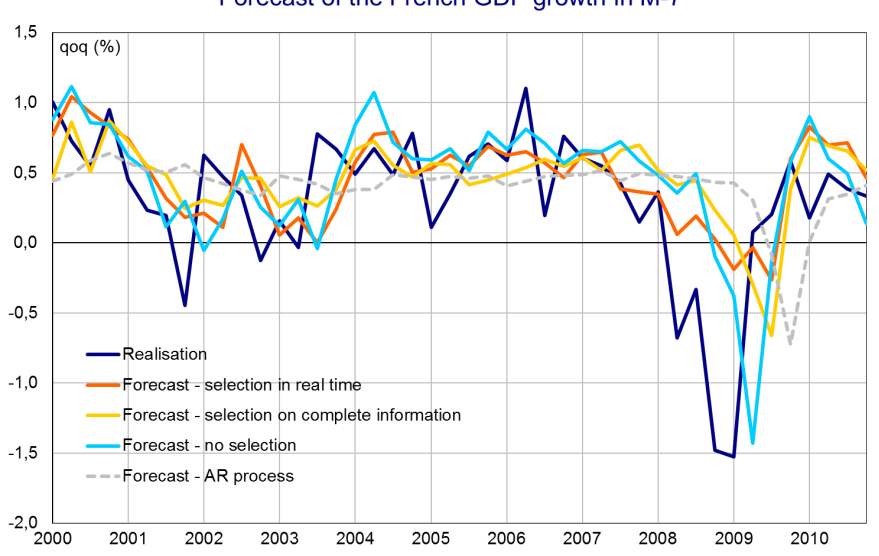

Forecast of the French GDP growth in M-5

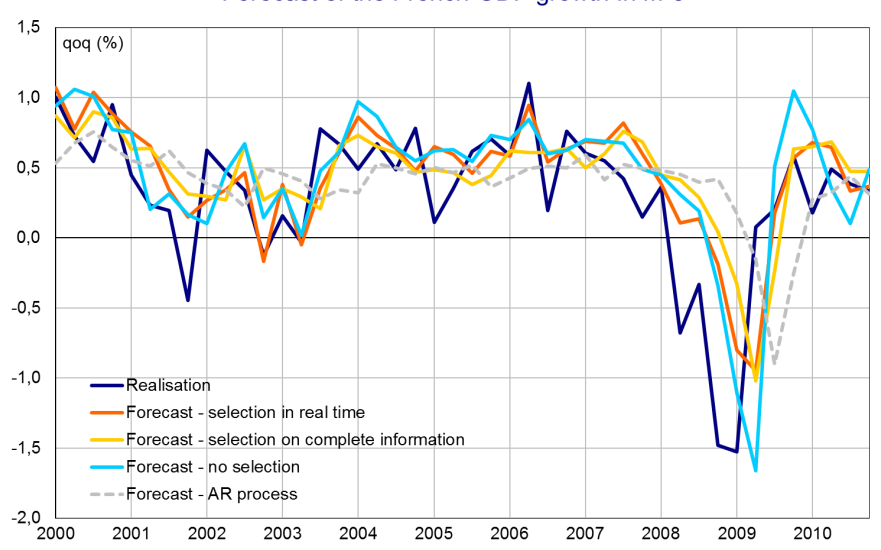

Forecast of the French GDP growth in M-3

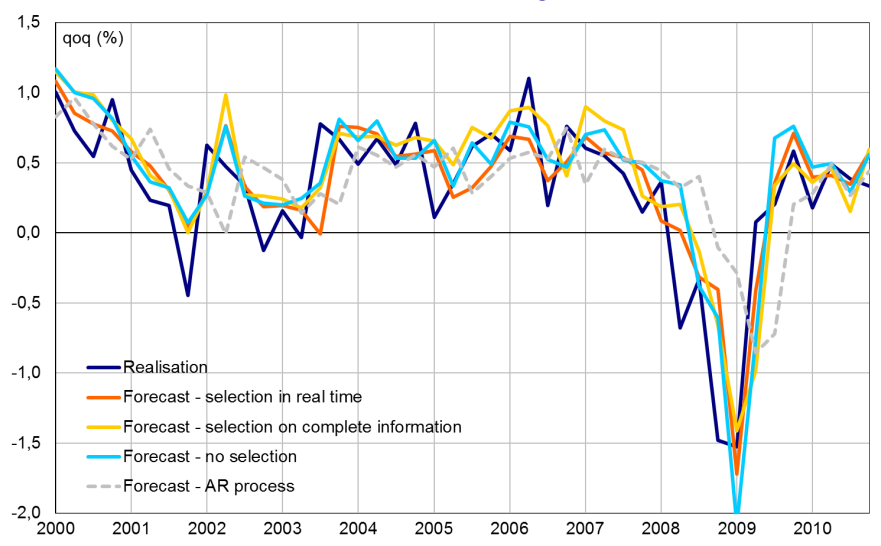

Forecast of the French GDP growth in M-1

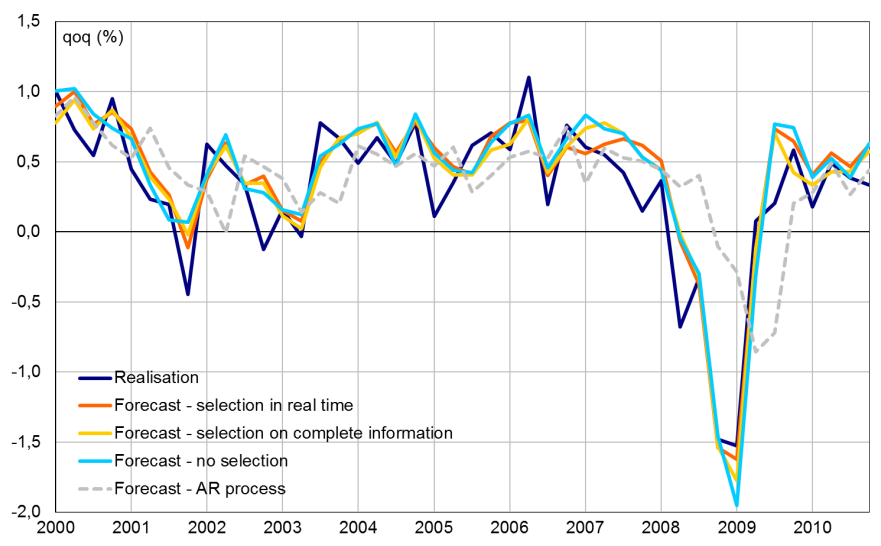

Forecast of the French GDP growth in M-6

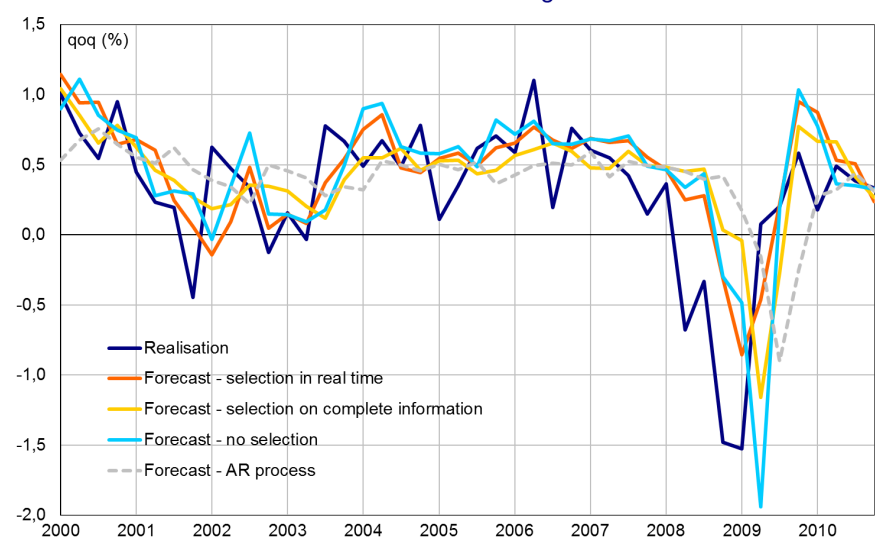

Forecast of the French GDP growth in M-4

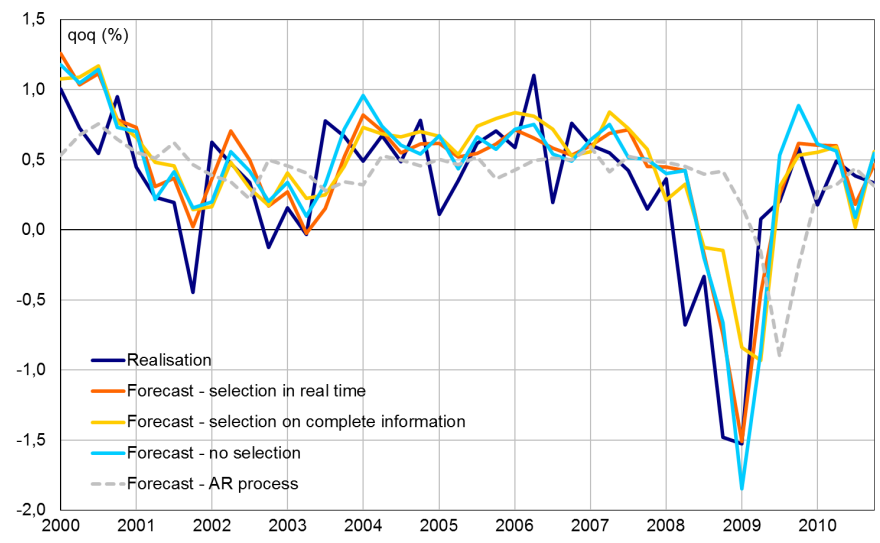

Forecast of the French GDP growth in M-2

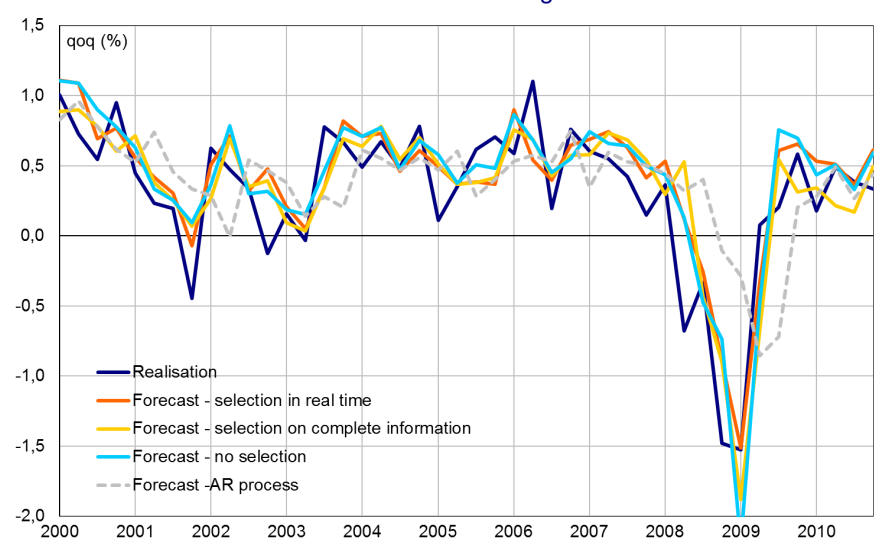

Forecast of the French GDP growth in M-0

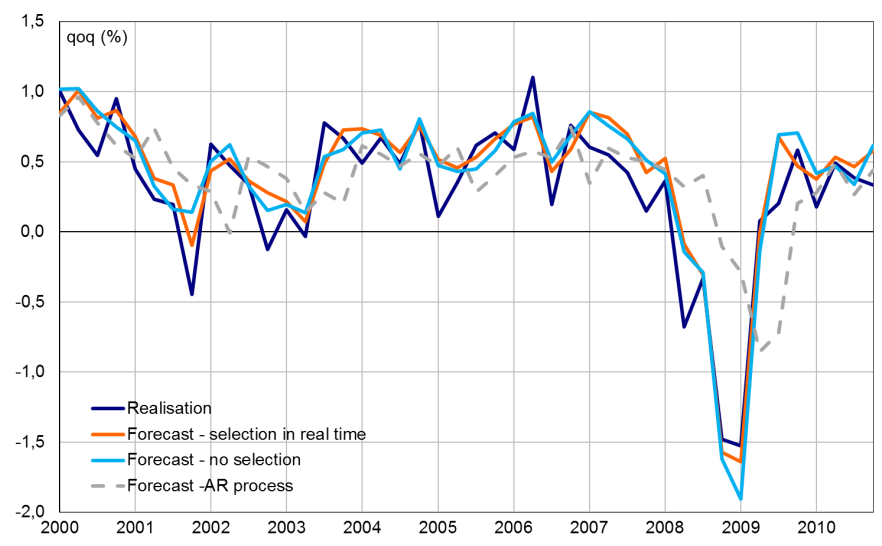

25 